\title{
First record of the Neotropical myrmicine ant genus Kempfidris Fernández, Feitosa \& Lattke, 2014 (Hymenoptera: Formicidae) for Peru
}

\author{
Gabriela P. Camacho ${ }^{1 *}$ and Rodrigo M. Feitosa ${ }^{2}$ \\ 1 Programa de Pós-Graduação em Entomologia, Universidade Federal do Paraná, 81531-980, Curitiba, PR, Brazil \\ 2 Departamento de Zoologia, Universidade Federal do Paraná, Caixa Postal 19020, 81531-980, Curitiba, PR, Brazil \\ * Corresponding author. E-mail: gabipcamacho@ymail.com
}

\begin{abstract}
The ant genus Kempfidris comprises a single rarely collected species, Kempfidris inusualis (Fernández, 2007). The record presented here represents an extension of this species distribution in the Amazon Basin of approximately $593 \mathrm{~km}$ to the south. The specimens were collected in the leaf litter of a seasonally flooded area. This record consolidates the hypothesis that $K$. inusualis is a ground-dwelling species that inhabits leaf litter and probably nests in rotten logs or other dead wood. This finding highlights the importance of the choice of proper sampling methods to uncover the hidden fauna of a given locality.
\end{abstract}

Key words: Tambopata National Reserve; Amazon; Solenopsidini

The recently described ant genus Kempfidris Fernández, Feitosa \& Lattke, 2014 (Formicidae: Myrmicinae: Solenopsidini) comprises a single rarely collected species, Kempfidris inusualis (Fernández, 2007). Very little is known about the natural history of $K$. inusualis and the few observations suggest these ants are grounddwelling and use rotten logs as nesting sites (Fernández et al. 2014). The workers are similar in size though some discrete morphological variation can be found among specimens along their geographical range (Fernández 2007).
Kempfidris inusualis was originally described as a species in the genus Monomorium Mayr, 1855 despite its singular combination of characters, which raised questions about its position within the Myrmicinae. After further study of morphological and molecular evidence, Fernández et al. (2014) recognized this species' distinctiveness and created the new, monotypic genus Kempfidris. At that time, the relationships among the main lineages of Myrmicinae were poorly known, including the position of Kempfidris. More recently, Ward et al. (2015) presented an evolutionary study of the subfamily based on molecular markers, recovering a robust phylogeny that positions Kempfidris as the sister group of Tropidomyrmex Silva, Feitosa, Brandão \& Diniz, 2009 in the newly delimited tribe Solenopsidini. Their results corroborated the artificial nature of the cosmopolitan and morphologically diverse genus Monomorium, already suspected as polyphyletic by various authors (Bolton 1987; Heterick 2003; Fernández et al. 2014). Additionally, although the previous placement of K. inusualis was in Monomorium, the former seems to be more closely related to Solenopsis than to Monomorium.

The known distribution of Kempfidris (Table 1) suggests that it is a predominantly Amazonian genus recorded from Venezuela, Ecuador, the Brazilian Amazon, and at single locality on the Atlantic Forest of northeastern Brazil (Fernández et al. 2014). Due

Table 1. Distribution records of Kempfidris inusualis in South America.

\begin{tabular}{llll}
\hline Localities & Latitude & Longitude & Source \\
\hline Puerto Maldonado, Peru & $12^{\circ} 51^{\prime} 15.4^{\prime \prime} \mathrm{S}$ & $069^{\circ} 22^{\prime} 15.9^{\prime \prime} \mathrm{W}$ & New record \\
Barrolândia, Bahia & $16^{\circ} 05^{\prime} 57^{\prime \prime} \mathrm{S}$ & $039^{\circ} 16^{\prime} 14^{\prime \prime} \mathrm{W}$ & Fernández et al. (2014) \\
Benjamim Constant, Amazônia & $04^{\circ} 22^{\prime} 28^{\prime \prime} \mathrm{S}$ & $070^{\circ} 01^{\prime} 47^{\prime \prime} \mathrm{W}$ & Fernández et al. (2014) \\
Ecuador, Napo, Limoncocha & $00^{\circ} 24^{\prime} 39^{\prime \prime} \mathrm{S}$ & $076^{\circ} 37^{\prime} 26^{\prime \prime} \mathrm{W}$ & Fernández et al. (2014) \\
Rondônia, Porto Velho, Mutum & $09^{\circ} 35^{\prime} 44^{\prime \prime} \mathrm{S}$ & $065^{\circ} 04^{\prime} 00^{\prime \prime} \mathrm{W}$ & Fernández et al. (2014) \\
Amazonas, Maroa, Venezuela & $02^{\circ} 43^{\prime} 48^{\prime \prime} \mathrm{N}$ & $067^{\circ} 32^{\prime} 34^{\prime \prime} \mathrm{W}$ & Fernández et al. (2014) \\
\hline
\end{tabular}


to its high topographical complexity, Peru presents a great number of ecoregions and vegetation formations that include arid regions, high altitude ecosystems and rainforests (Reynel et al. 2013). Furthermore, Peruvian fauna and flora are known for its impressive diversity, rendering the country one of the most species-rich regions of the world, with high levels of endemism (Reynel et al. 2013).

Bezdecková et al. (2015) recently published a comprehensive species list of ants for Peru, which included 592 species. Guenárd and Economo (2015) presented additional records that increased the number of Peruvian ant species to 679 . However, despite recent efforts to reveal the ant fauna of Peru, little collecting has been done in Peru as compared to Brazil, Colombia or Ecuador, and it is expected that Peru's diversity is under sampled. All this indicates that our knowledge of Peruvian ant diversity is inadequate and many new records, as well as taxonomic novelties, are to be expected with additional sampling. This is the case with Kempfidris, even though its presence was predicted by its distribution range (Bezdecková et al. 2015). In this work, we present the first record of $K$. inusualis for Peru, extending the distribution limits of this enigmatic genus in South America. We also discuss the importance of proper sampling methods to uncover the hidden ant fauna.

The specimens reported here were collected on the south bank of the Tambopata River in the Tambopata National Reserve, department of Madre de Dios, Peru. The individuals were collected along the Condenado I trail $\left(12^{\circ} 51^{\prime} 15.4^{\prime \prime} \mathrm{S}, 069^{\circ} 22^{\prime} 15.9^{\prime \prime} \mathrm{W}\right)$, located in an area subject to seasonal flooding near the Sachavacayoc Centre lodge. Thirteen individuals of Kempfidris inusualis were collected from a leaf litter sample processed with a mini-Winkler extractor (Fisher 1996). The specimens came specifically from an area at $209 \mathrm{~m}$ above the sea level that known to flood during the raining season (Espinoza Villar et al. 2009). Workers were captured between 19-31 July 2012, during the field course Curso de Hormigas Neotropicales, organized by the Centro de Ecología y Biodiversidad (CEBIO) based in Lima. The specimens were stored for proper triage until recently, when a careful examination proved that the individuals belong to $K$. inusualis, representing the first record of the genus for Peru (Figure 1).

The specimens are now deposited in the Coleção Entomológica Padre Jesus Santiago Moure of the Universidade Federal do Paraná (DZUP), Curitiba, PR, Brazil, under the voucher code ANT-CO01K.

High resolution images presented here were obtained with a LEICA DFC295 digital camera attached to a LEICA M125 stereoscopic microscope. Photos were combined using Zerene Stacker software at the DZUP. Images were then processed as TIFF files in Adobe Photoshop CS5 ${ }^{\circledR}$ to enhance parameters of brightness and contrast. The geographical coordinates were imported from Google Earth 7.0.2 ${ }^{\circledR}$ after consulting previous records of Kempfidris in the literature and then exported to QGis 2.12.3 ${ }^{\circledR}$ for generating the distribution map, using Natural Earth ${ }^{\circledR}$ free vector and raster map data (available at http://www.naturalearth.com).

The most outstanding morphological feature of Kempfidrisinusualis (Figure1) is the series of minute, hairbearing tubercles or cylindrical pegs on the abdominal apex that appear to be an autapomorphy for the genus (Fernández et al. 2014). The species is also characterized by a head that is longer than wide, antennal insertions situated relatively close together, and scapes that fail to reach the vertexal border. In lateral view, the metanotal groove is very deep and well-marked. The propodeal spiracle is circular, with its opening directed posteriorly. The petiole has a well-differentiated peduncle and node, the node with subparallel anterior and posterior faces, and a convex dorsum.

The record presented here extended the distribution of Kempfidris inusualis in the Amazon Basin by approximately $593 \mathrm{~km}$ to the south from the previously known southernmost record in Porto Velho, Rondônia, Brazil (Fernández et al. 2014). The specimens were collected in an environment very similar to those from where most of the other known specimens have been recorded, i.e. in leaf litter in seasonally flooded areas. Interestingly, the workers from Peru were collected in July, the same time of the year in which all the other known specimens of $K$. inusualis were collected, which coincides with the lowest levels of rainfall for the region ( $5 \%$ of the mean expected annual precipitation) (Espinoza Villar et al. 2009). Fernández et al. (2014) suggested that these ants might be more active in this period, which coincides with the low level of the rivers in the Amazon Basin. It is conceivable that these ants could be migrating into the canopy during the rainy season to escape flooding and come back down again to forage on the newly exposed soil and occupy new nesting sites provided by logs and sticks that have remained as the waters recede (John Lattke, personal communication). The fact that the ants reported here were collected with Winkler extractors consolidate the hypothesis that $K$. inusualis is a ground dwelling species that inhabits the leaf litter and probably nests in rotten logs or sticks, corroborating previous observations in the field (Fernández et al. 2014). In addition, the Peruvian specimens of $K$. inusualis are relatively uniform in size and general aspect when compared to those recorded in other localities.

It is noteworthy that despite the several ant inventories historically carried out in Peru (see Bezdecková et al. 2015), Kempfidris inusulalis has never 


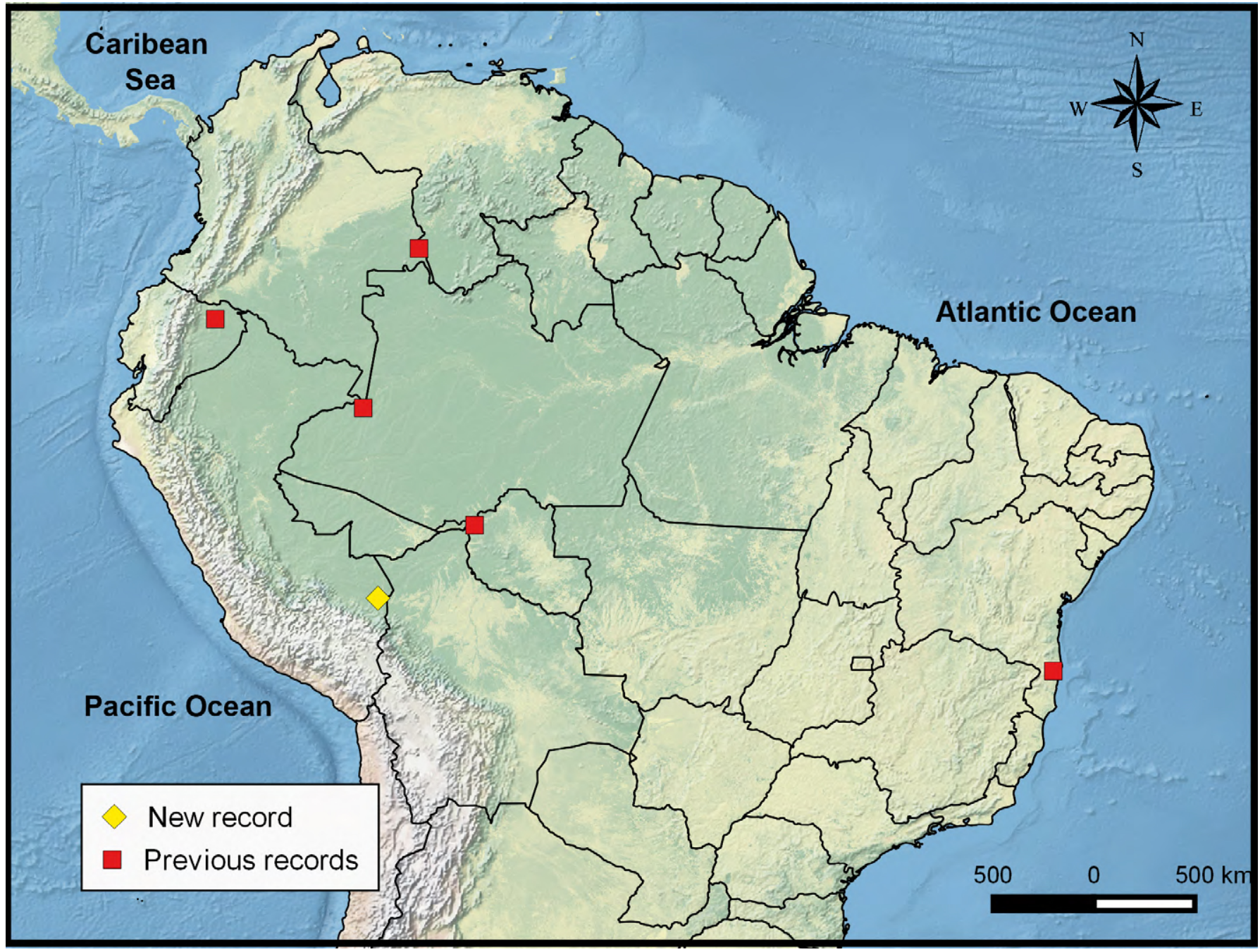

Figure 1. Distribution of Kempfidris inusualis in South America.

been recorded so far. Many surveys of the ant fauna use pitfall traps (e.g., Campos et al. 2011; Frizzo et al. 2012), due to their simplicity and low cost, especially when random and quantitative samples are necessary (Souza et al. 2012). However, collecting ants by the Winkler extractor has a greater potential to catch a considerable number of smaller ants and to reach a higher total species richness and ant abundance when compared to pitfall traps (Ivanov and Keiper 2009; Ivanov et al. 2010; Lopes and Vasconcelos 2008; Sabu et al. 2011; Silva et al. 2013). The first record of $K$. inusualis for Peru highlights the importance of the choice of proper sampling methods to uncover the hidden fauna of a given locality (even the well-sampled places), as well as to discover undescribed taxa. It is not possible to rule out the presence of this species in other collections, because of its morphological resemblance to species of Solenopsis and Monomorium, which can lead to misidentifications, even from experienced myrmecologists.

\section{ACKNOWLEDGEMENTS}

We would like to thank Gabriel Melo (DZUP) for providing the equipment for the acquisition of highresolution images. We also thank John Lattke who kindly agreed to read previous versions of this article, and Robert Forsyth, that made important suggestions that improved a lot the manuscript. GPC (fellowship 140338/2014-4) thanks the Conselho Nacional de Desenvolvimento Científico e Tecnológico (CNPq) for the support.

\section{LITERATURE CITED}

Bezděčkovā, K., P. Bezděčkovā and I. Machar. 2015. A checklist of the ants (Hymenoptera: Formicidae) of Peru. Zootaxa 4020(1): 101-133. doi: 10.11646/zootaxa.4020.1.4

Campos R.I., H.L. Vasconcelos, A. Andersen, T.L.M. Frizzo and K.C. Spena. 2011. Multi-scale ant diversity in savanna woodlands: an intercontinental comparison. Austral Ecology 36(8): 983-992. doi: 10.1111/j.1442-9993.2011.02255.x

Espinoza Villar, J.C., J. Ronchail, J.L. Guyot, G. Cochonneau, F. Naziano, W. Lavado, E. De Oliveira, R. Pombosa and P. Vauchel. 

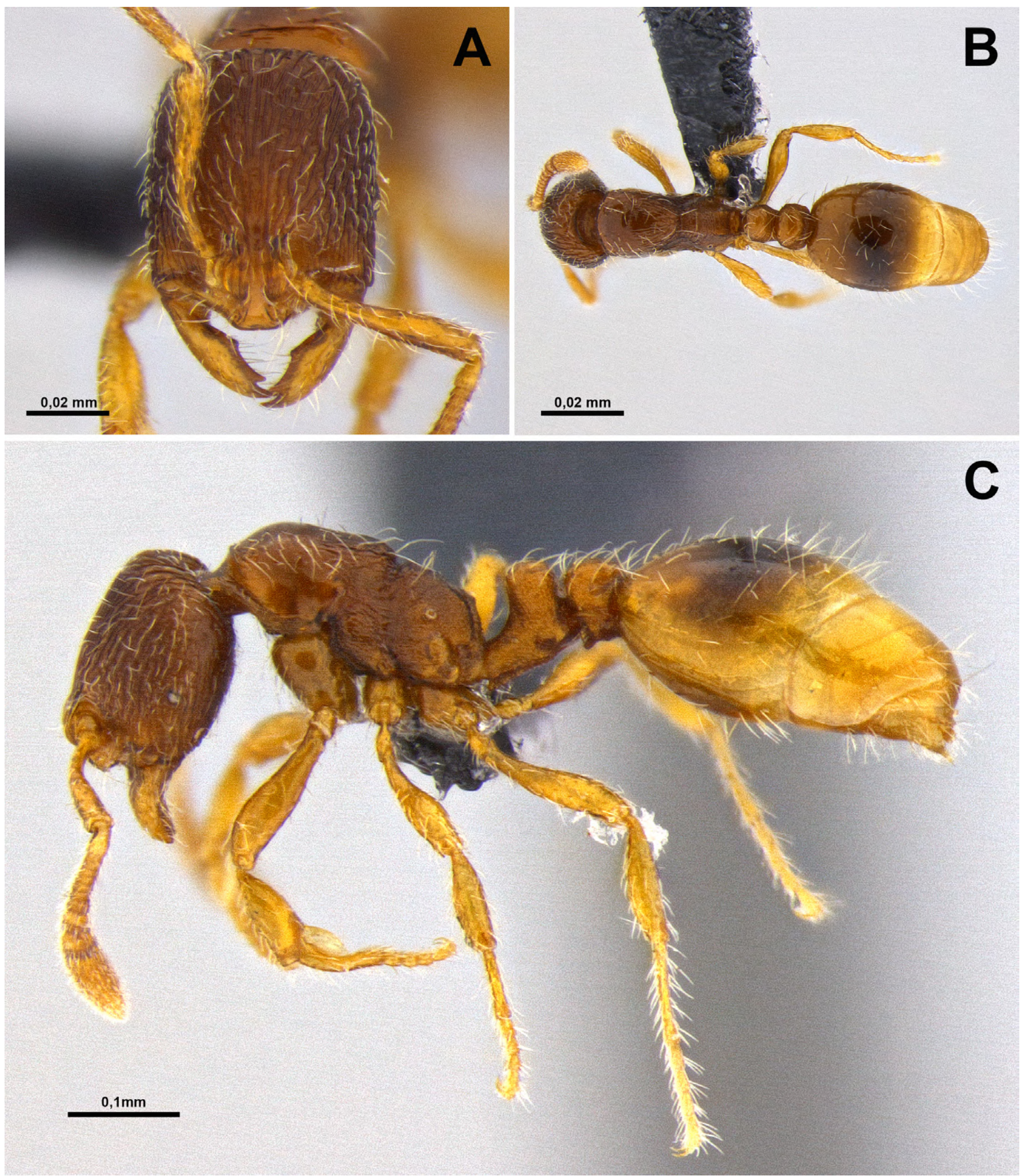

Figure 2. Kempfidris inusualis worker from Peru. A: head in frontal view; B: body in dorsal view; C: body in lateral view.

2009. Spatio-temporal rainfall variability in the Amazon Basin countries (Brazil, Peru, Bolivia, Colombia and Ecuador). International Journal of Climatology 29: 1574-1594. doi: 10.1002/ joc.1791

Fernández, F., R.M. Feitosa and J. Lattke. 2014. Kempfidris, a new genus of myrmicine ants from the Neotropical region (Hymenoptera: Formicidae). European Journal of Taxonomy 85: 1-10. doi: $10.5852 /$ ejt.2014.85
Fernández, F. 2007. Two new South American species of Monomorium Mayr with taxonomic notes on the genus; pp. 128-145, in: R.R. Snelling, B.L. Fisher and P.S. Ward (eds.). Advances in ant systematics (Hymenoptera: Formicidae): homage to E. O. Wilson - 50 years of contributions. Memoirs of the American Entomological Institute 80.

Frizzo, T.L.M., R.I. Campos and H.L. Vasconcelos. 2012. Contrasting effects of fire on arboreal and ground-dwelling ant communities 
of a Neotropical Savanna. Biotropica 44(2): 254-261. doi: 10.1111 /j.1744-7429.2011.00797.x

Guenard, B and E.P. Economo. 2015. Additions to the checklist of the ants (Hymenoptera: Formicidae) of Peru. Zootaxa 4040 (2): 225-235. doi: 10.11646/zootaxa.4040.2.8

Ivanov, K. and J. Keiper. 2009. Effectiveness and biases of Winkler litter extraction and pitfall trapping for collecting grounddwelling ants in northern temperate forests. Environmental Entomology 38(6): 1724-1736. doi: 10.1603/022.038.0626

Ivanov, K., J. Milligan and J. Keiper. 2010. Efficiency of the Winkler method for extracting ants (Hymenoptera: Formicidae) from temperate-forest litter. Myrmecological News 13: 73-79.

Lopes, C.T. and H.L. Vasconcelos. 2008. Evaluation of three methods for sampling ground-dwelling ants in the Brazilian Cerrado. Neotropical Entomology 37(4): 399-405. doi: 10.1590/S1519566X2008000400007

Mayr, G. 1855. Formicina austriaca. Beschreibung der bisher im österreichischen Kaiserstaate aufgefundenen Ameisen, nebst Hinzufügung jener in Deutschland, in der Schweiz und in Italien vorkommenden Ameisen. Verhandlungen des Zoologisch-Botanischen Vereins in Wien 5: 273-478.

Reynel, C., R.T. Pennington, and T. Särkinen. 2013. Cómo se formó la diversidad ecológica del Perú. Lima: Imprenta Jesús Bellido M. 412 pp.

Sabu, T.K., R.T. Shiju, K.V. V. and S. N. 2011. A comparison of the pitfall trap, Winkler extractor and Berlese funnel for sampling ground-dwelling arthropods in tropical montane cloud forests.
Journal of Insect Science 11(28): 1-19. doi:10.1673/031.011.0128

Silva, R.R., R.M. Feitosa, C.F.R. Brandao and V.L. Freitas. 2013. The first Leptanilloides species (Hymenoptera: Formicidae: Leptanilloidinae) from eastern South America. Journal of Natural History 47(31-32): 2039-2047. doi: 10.1080/00222933.2012.763058

Silva, R.R., R.M. Feitosa, C.R.F. Brandão and J.L.M. Diniz. 2009. Tropidomyrmex elianae, a new myrmicine ant genus and species from Brazil, tentatively assigned to Solenopsidini (Hymenoptera, Formicidae). Zootaxa 2052: 32-48.

Souza, J.L.P., F.B. Baccaro, V.L. Landeiro, E. Franklin and W.E. Magnusson. 2012. Trade-offs between complementarity and redundancy in the use of different sampling techniques for ground-dwelling ant assemblages. Applied Soil Ecology 56: 63-73. doi: 10.1016/j.apsoil.2012.01.004

Ward, P.S., S.G. Brady, B.L. Fisher and T.R. Schultz. 2015. The evolution of myrmicine ants: phylogeny and biogeography of a hyperdiverse ant clade (Hymenoptera: Formicidae). Systematic Entomology 40(1): 61-81. doi: 10.1111/syen.12090

Author contributions: RMF collected the data, GPC prepared the specimens high resolution images and the distribution maps, GPC and RMF wrote the text.

Received: 19 April 2016

Accepted: 25 May 2016

Academic editor: Jason Gibbs 